\title{
CLUBE DE LEITURA NA BIBLIOTECA ESCOLAR: MANUAL DE INSTRUÇÕES
}

\author{
CLUBE DE LECTURA EN LA BIBLIOTECA DE LA \\ ESCUELA: MANUAL DE INSTRUCIONES
}

\begin{abstract}
Sueli Bortolin - bortolin@uel.br Doutora em Ciência da Informação pela Universidade Estadual Paulista (UNESP/Marília). Professora do Programa de Pós-Graduação em Ciência da Informação da Universidade Estadual de Londrina (UEL).

Zineide Pereira dos Santos - zineide.santos@ifpr.edu.br Especialista em Gestão de Biblioteca Escolar pela Universidade Estadual de Londrina (UEL). Bibliotecária no Instituto Federal do Paraná (IFPR/Campus Paranavaí).
\end{abstract}

\section{RESUMO}

Introdução: O presente estudo aborda algumas considerações sobre o ato de ler do aluno adolescente, a função do mediador da leitura na biblioteca escolar e suas ações para manter o aluno leitor e conquistar novos leitores. Com base nesse contexto propomos a criação de um Clube de Leitura como um mecanismo capaz de aproximar leitura, leitores e o mediador da leitura tornando a biblioteca um organismo vivo dentro da escola.

Objetivo: Propor a criação de um mecanismo que possa fomentar a leitura na biblioteca escolar, bem como subsidiar o mediador da leitura na iniciação de jovens para o gosto da leitura.

Metodologia: Bibliográfica com estudos da literatura que lidam com a criação e manutenção de um Clube de Leitura, bem como a abordagem dos termos: leitura e mediador de leitura na biblioteca escolar.

Resultados: Elaboração de um Manual com Instruções para a criação e manutenção de um Clube de Leitura na biblioteca escolar com a missão, os valores, a visão, normas e regulamentos, sugestões de atividades culturais, bem como, de livros e filmes que possam subsidiar os mediadores de leitura.

Conclusões: Aponta para a necessidade da preparação do bibliotecário escolar, pois é a pessoa que está à frente da biblioteca, devendo ser um profissional de referência no ato da leitura e também um dos responsáveis pela formação e manutenção de leitores. 
Sueli Bortolin; Zineide Pereira dos Santos

Clube de leitura na biblioteca escolar: manual de instruções

Palavras-chave: Mediador da leitura. Clube de leitura. Leitores adolescentes na escola.

\section{INTRODUÇÃO}

A pesquisa Retratos da Leitura no Brasil 3 (2012) aponta um déficit de leitura sobretudo nos adolescentes. Nesta pesquisa, a biblioteca escolar é percebida como um espaço que perde sua utilidade primária, que é a leitura, aparecendo no contexto escolar apenas como uma extensão da sala de aula ou mais um ambiente dentro da escola.

Durante o percurso dessa investigação teve-se a oportunidade de perceber que o percentual de pais que leem em casa para ou com os seus filhos é ínfimo, quando alcançam a adolescência esse ponto de sua vida intelectual fica por conta dos professores ou deles mesmos.

Outro aspecto da referida pesquisa que desperta a atenção é que a criança no início de sua vida escolar, isto é, na Educação Infantil são estimuladas pelos professores com ações de leitura em sala de aula ou na biblioteca. São incentivadas com atividades culturais como a Hora do Conto e outras atividades relacionadas ao livro e à leitura. Depois dessa fase a escola se preocupa muito pouco em propor atividades de leitura prazerosa e elas deixam de fazer parte da rotina escolar.

Diante dessa reflexão, a biblioteca escolar tem urgência em se (re)afirmar, não somente como local de estudo e pesquisa, mas principalmente, como um ambiente que propicia espaço para a leitura recreativa, enfim, um lugar para permanência do leitor-estudante.

Nesse sentido, a proposta da criação e gestão de um clube de Leitura, com a presença do mediador, é uma iniciativa que poderá contribuir tanto para a iniciação e formação de leitores, quanto alargar o contato desses alunos com o livro e a literatura.

Neste estudo pretendeu-se levar ao educando do Ensino Médio, que ainda não é um leitor assíduo, instrumentos que permitam a sua aproximação mais intensa e permanência no mundo da leitura porque é fundamental "[...] antes de mais nada, aprender a ler o mundo, compreender o seu contexto, não numa manipulação mecânica de palavras, mas numa relação dinâmica que vincula linguagem e realidade." (FREIRE, 1986, p. 8). 
Pensando dessa forma a proposta de um clube de leitura para a mediação da leitura na biblioteca escolar é um instrumento fundamental para o bibliotecário e para o leitor.

Almeja-se com as ideias aqui discutidas subsidiar acadêmicos de Letras, Pedagogia, Biblioteconomia e áreas afins, para que percebam a sua importância como mediador de leitura, responsável em ampliar o número leitores na escola, instituição esta que é, e sempre será, mesmo que de forma limitada, o principal espaço estimulador de mudanças no indivíduo, levando-o abandonar seu papel de espectador passivo dentro da escola.

Para tanto, buscou-se na literatura assuntos relacionados com a leitura, a formação do leitor, a ação do mediador, o espaço para a prática da leitura e o clube de leitura.

\section{LEITURA, LEITOR E MEDIAÇÃO DA LEITURA}

Para iniciar essa investigação foi necessário buscar-se na literatura pertinente concepções e autores que tratavam a leitura e mediação da leitura, especialmente aquela voltada para o entretenimento e lazer. Nesse sentido, Orlandi $(1988$, p. 7) faz a seguinte reflexão:

Leitura vista em sua acepção mais ampla, pode ser entendida como atribuição de sentido às coisas. [...] No sentido mais restrito, leitura pode significar a construção dum aparato teórico e metodológico de aproximação dum texto.

Avalia-se que com o conhecimento desse aparato o leitor passa a se aprofundar nos mistérios de um texto. $O$ ato de ler só deixará de ser uma atividade meramente mecânica no momento em que o leitor pratica uma ação reflexiva. Barbosa (1994, p. 116) afirma que "Num mundo onde a escrita é um meio importante na circulação de ideias, é fundamental a análise do ato de ler." Ainda segundo o autor,

Ler é uma atividade ideovisual. Podemos dizer que a leitura depende do que está diante e atrás dos nossos olhos. A leitura é uma atividade visual porque para ler é necessário haver um texto diante dos olhos, uma certa claridade e, às vezes, um par de óculos. Mas, a 
leitura é mais que um exercício dos globos oculares, pois se apóia, por uma lado, no que o leitor recebe através do seu sistema de visão e, por outro, nas informações que o leitor tem disponíveis na sua cabeça, na sua estrutura cognitiva. (BARBOSA, 1994, p. 116).

Tomando como base o pensamento de Barbosa, pode-se pensar no seguinte exemplo ilustrativo: um aluno de Ensino Médio recebe um artigo científico a respeito de uma determinada doença rara. Se esse aluno não conhece ou não teve nenhuma informação anterior dessa enfermidade ele precisará de informações complementares. Essa leitura torna-se muito mais difícil de ser entendida porque ele não tem conhecimento anterior para apoiar sua leitura atual. Se esse mesmo aluno tivesse assistido um filme que tratasse dessa doença rara, teria possibilidade de maior compreensão da doença e o texto científico se tornaria menos complexo.

Uma leitura espontânea e desprovida da obrigação escolar, além do entretenimento, também traz informação e conhecimento ao leitor. Esse conhecimento fica, então, armazenado na memória e, em momento futuro, essa leitura pode vir a complementar o conteúdo escolar dando suporte para uma melhor compreensão do texto lido, ampliando seu conhecimento de mundo.

Silva (2002, p. 43) afirma em suas reflexões que "[...] o leitor executa um ato de compreender o mundo. De fato, o propósito básico de qualquer leitura é a apreensão dos significados mediatizados ou fixados pelo discurso escrito [...]". Entre outras possibilidades de conceito para leitura, ele defende que "Ler é, em última instância, não só uma ponte para a tomada de consciência, mas também um modo de existir no qual o indivíduo compreende e interpreta a expressão registrada pela escrita e passa a compreender-se no mundo." (SILVA, 2002, p. 45).

A leitura é uma atividade fundamental para qualquer área do conhecimento humano, sendo essencial à própria vida, pois contribui com a formação do homem. O patrimônio simbólico do homem contém uma herança cultural registrada pela escrita e a leitura é uma das formas de o homem se situar no mundo de forma a dinamizá-lo. A leitura está inteiramente relacionada com o sucesso do Ser que aprende, tornando-se um dos principais instrumentos que permite ao homem comunicar-se com os outros homens e, assim, chegar ao conhecimento. Portanto, facilitar a aprendizagem por meio da leitura é um dos principais recursos de que se dispõe para combater a massificação. Freire (1986, p. 22) explica que 


\begin{abstract}
Antes da leitura da palavra, está a leitura de mundo e através da leitura da palavra continuaremos a ler o mundo. É necessária a prática em "escrever e reescrever" o mundo para que possamos transformá-lo. O ato de ler implica percepção crítica, interpretação e reescrita do lido. Mesmo em se tratando da escrita, o processo da leitura está mais ligado à experiência pessoal do que ao conhecimento sistemático da língua.
\end{abstract}

Compreender esse conceito tão aberto na década de 1980 era mais complexo, mas na atualidade com as concepções plurais de textos não é aceitável conceitos e práticas restritivas. Nesse sentido, Martins (1983, p. 73) defende:

[...] quanto mais lemos de modo abrangente, mais estaremos também favorecendo nossa capacidade de leitura do texto escrito. Sem dúvida, o intercâmbio de experiências de leituras desmistifica a escrita, o livro, levando-nos a compreendê-los e apreciá-los de modo mais natural, e certamente estaremos assim fortalecendo nossas condições de leitores efetivos das inumeráveis mensagens do universo em que vivemos.

Nesse sentido, pode-se deduzir que o leitor não nasce pronto, ou faz-se de um instante para o outro, ou que em determinado momento ele está pronto. Essa mediação entre leitura, leitores e livros acontece gradativamente (partindo- se do pressuposto de que toda criança sabe ler, porque já possui o conhecimento de mundo), o contato com a literatura e, consequentemente, com a leitura da literatura o faz leitor. De acordo com Parreiras (2011, p. 26), "A leitura começa no espaço da intimidade (em casa) e depois alcança o espaço público (a escola, a biblioteca). Posteriormente, cabe à escola dar prosseguimento ao processo de mediação da leitura tão necessário para o aluno."

É corriqueiro na escola se utilizar da leitura com o pretexto de ensinaraprender e atrelada a obrigatoriedade de interpretação e exercícios, logo, ela não se torna mais atrativa nem livre, mas sim curricular.

Partindo da premissa de que se há leitura há leitor, então o que é leitor e quem é leitor? Para Britto (2011, p. 18), "[...] uma definição primeira, da qual não se pode escapar, é a de que leitor é aquele que lê com certa frequência, para estudar, para informar-se, para conhecer, experimentar vida, fazer coisas."

Assim, pressupomos que leitor não é simplesmente a criança, o adolescente ou um adulto que saiba ler. Ser leitor implica em "[...] uma atitude diante das coisas do mundo. O leitor não é leitor porque pode ler (ainda que isso seja condição 
determinante): ele se constitui quando, para além do texto, faz a leitura do mundo, para usar a consagrada expressão de Paulo Freire." (BRITTO, 2011, p. 19).

De qual leitura estamos falando? O aluno pode aprender com histórias em quadrinhos ou um romance policial? Essa modalidade de leitura contribui para o aprendizado?

Sabe-se que a gramática é necessária, pois nos proporciona suporte para 0 bom desempenho da escrita, visto que sem ela fica impossível a comunicação (não apenas na escola), assim como sem a Matemática que é essencial para um bom desempenho financeiro ou a Biologia que nos ajuda a compreender como se dá a formação do corpo humano, das plantas e dos seres vivos em geral. Todas essas disciplinas são importantes e necessárias para a nossa formação e fazem parte do currículo escolar, portanto, obrigatórias. Mas, somente elas podem proporcionar aprendizado? Candido (1972, p. 805), em seu texto A Literatura e a Formação do Homem, defende que "Talvez os contos populares, as historietas ilustradas, os romances policiais ou de capa-e-espadas, as fitas de cinema, atuem tanto quanto a escola e a família na formação de uma criança e de um adolescente."

Em nenhum momento a pesquisadora ou o autor afirmam que o aluno deva ler somente o que Ihe agrada, mas que a leitura da literatura quando lida de forma espontânea e livre leva à aprendizagem. Nisso consiste o conhecimento, a intervenção e a ação do bibliotecário leitor-mediador.

Não se quer na literatura recreativa a obrigatoriedade para que o leitor tenha a liberdade de escolher e ler o livro que mais lhe agrada, no momento e no lugar que Ihe for mais favorável.

No contexto escolar todos somos leitores. Quando conversamos ou contamos o enredo da nossa leitura ao outro, somos também mediadores; assim, entendemos por mediador escolar todos que ali atuam: técnicos, professores, bibliotecários e alunos. De acordo com Barros (2006, p. 18), "[...] somos todos leitores, em maior ou menor medida. Até mesmo leitores que não sabem ou que não podem ler o alfabeto; leitores do mundo, todos."

Deve-se aqui concordar com Barros quando afirma que todos somos leitores e vale acrescentar que temos uma carga de experiência de leitura acumulada que, em algum momento, ela será compartilhada, portanto mediada.

Quando se trata do bibliotecário ou outro profissional que atua na biblioteca escolar com mediação da leitura literária para crianças e adolescentes é necessário 
ser diferente. Esse profissional precisa ter um diferencial: gostar do que faz, conhecer o seu público e seu acervo, ler e gostar de ler e, sobretudo, ser um leitor apaixonado.

Evidentemente que o mesmo livro ou história não vai exercer um fascínio semelhante em leitores diferentes. Quando lemos um livro que prende a nossa atenção, logo queremos compartilhar esse mesmo gosto e experiência. Esta paixão que passamos ao outro quando falamos de um livro ou de um poema lido pode ser o "fio condutor" que levará outros leitores a partilhar do mesmo interesse. Estes ao levar seus amigos e amigos dos amigos a experimentar uma sensação semelhante, tecerão uma rede de leitores-mediadores formando uma espécie de clube.

Essa conduta é típica nos adolescentes, como afirmam Borges e Bortolin (2006, p. 140), "Na fase adulta [e na adolescência] somos influenciados [...] por um amigo e mais fortemente pela mídia."

Não só a televisão, a web e outras formas de entretenimento, com sua ludicidade, desviam a atenção dos adolescentes da leitura, mas infelizmente, também, o bibliotecário ou o profissional que atua nesse espaço, que em sua maioria, não está habilitado para exercer esta função, não se atualiza e continua "[...] a acreditar, ingenuamente, que livro, jornal e revista são os únicos materiais de leitura, ignorando, perigosamente, a "leitura" que os jovens fazem pela parafernália eletrônica e que lhes dá prazer, porque é lúdica, é jogo.” (BARROS, 2006, p. 19).

Em princípio, a mediação da leitura na biblioteca fica a cargo do bibliotecário; portanto, ele precisa estar atento ao comportamento e ao gosto dos adolescentes e suas mudanças. Ontem, os meninos brincavam com carrinho de rolimã e bolinha de gude, as meninas de bonecas e casinha, hoje são os jogos eletrônicos, amanhã serão outras brincadeiras e outras tecnologias.

A indústria de entretenimento está em constante movimento na busca de diversão. No mesmo sentido, o mercado editorial tem mudado também o seu modo de perceber o gosto das crianças e adolescentes e investindo em novos formatos mais atrativos. Também nós bibliotecários, temos o compromisso de ficar atentos diante das mudanças do mercado das inovações tecnológicas.

Para conservar, formar e despertar o gosto pela leitura nos adolescentes é necessário também mudar, não só o profissional que está à frente da biblioteca, mas também os espaços de leituras, o acervo, a organização e os diversos suportes que estão disponíveis. Segundo Bortolin (2006, p. 65) 


\begin{abstract}
A chamada leitura literária, para ser realizada com prazer, exige um conjunto de fatores, que pode variar desde a forma de organização do espaço em que se lê, e do acervo (impresso ou eletrônico) que está à disposição do leitor, à postura dos profissionais que fazem a mediação por meio de produtos, serviços e atividades culturais.
\end{abstract}

Sendo assim, é necessário ao bibliotecário, professor, diretor e/ou demais membros da escola, rever posicionamentos, repensar maneiras de agir e de ensinar. Repensar a biblioteca como espaço lúdico, propício e convidativo para a leitura de lazer. Transformar a biblioteca num espaço alternativo que lhe proporcione prazer.

Quem é o mediador que se quer na escola? Nela é "[...] o indivíduo que aproxima o leitor do texto. Em outras palavras é o [...] facilitador desta relação; que pode ser exercida por diferentes indivíduos [...] em diferentes espaços e em diferentes situações [...]" (BORTOLIN, 2006, p. 67).

O mediador focado neste trabalho é o bibliotecário. Ele tem a missão de buscar alternativas, não só como facilitador e leitor, mas também como uma das pessoas responsáveis pela formação de novos leitores. De acordo com a proposta desse estudo uma iniciativa exitosa na formação do leitor é o clube de leitura, pois ele é uma possível forma de disseminar o livro e os diversos textos, a leitura e levar novas pessoas a desenvolver o gosto pela leitura em um local confortável que propicia bem-estar.

\title{
3 PROCEDIMENTOS METODOLÓGICOS
}

Hoje, 2014, uma parte significativa da população brasileira é constituída de adolescentes entre 12 e 17 anos, isto é, indivíduos vivendo uma adolescência de múltiplas possibilidades. São mais de 21 milhões de jovens que representam cerca de $11 \%$ da população (O DIREITO..., 2011).

Eles, os adolescentes, "[...] vivenciam uma fase de construção de autonomia, identidade, aprendizagem e descoberta." (O DIREITO..., 2011, p. 14). É exatamente essa fase de descobertas e aprendizagem que abordamos nessa pesquisa, tendo como foco o gosto pela leitura.

Optamos nesse trabalho pela pesquisa bibliográfica tendo como apoio obras relevantes que abordassem a leitura e o clube de leitura. A busca revelou-se 
insatisfatória, visto que a literatura registrada sobre clubes de leitura, cujo objetivo é o fomento a leitura, tem se revelado mínima.

Vale destacar que o presente trabalho teve subsídio inicial a obra publicada em Portugal no ano de 2006 Clubes de Leitura para Adultos: manual para mentores, do filme Clube de Leitura da Jane Austen, do romance O clube do livro, do Grupo de Leitura para Adultos da Biblioteca Pública de Évora em Portugal e do Grupo de Leitura para jovens “Gaspachos de Letras” também da Biblioteca Pública de Évora.

Sendo assim, percebemos que a "Pesquisa bibliográfica não é mera repetição do que já foi dito ou escrito sobre certo assunto, mas propicia o exame de um tema sob novo enfoque ou abordagem, chegando a conclusões inovadoras." (MARCONI; LAKATOS, 2013, p. 57).

O livro Clubes de Leitura para Adultos: manual para mentores permitiu-nos conhecer propostas de atividades desenvolvidas em grupos; do Grupo de Leitura para Adultos da Biblioteca Pública de Évora foi possível desenvolver parâmetros para a biblioteca escolar realizar atividades que permitam a discussão de textos coletivamente.

Do Grupo de Leitura para Jovens "Gaspachos de Letras" também da Biblioteca Pública de Évora, retiramos um exemplo de planejamento de atividades.

O filme o Clube de Leitura da Jane Austen e o romance O Clube do livro, permitiu a percepção das possibilidades de leitura, a ação do mediador de leitura, bem como os debates e discussões de obras da literatura mundial.

Nesse sentido, podemos afirmar que a proposta, presente nessa pesquisa, para um Clube de Leitura tem o sentido de inovar e não apenas de repetir o que já foi criado.

\section{CLUBE DE LEITURA: PRIMEIRAS CONSIDERAÇÕES}

Ainda hoje, no Brasil e no mundo, a história do clube de leitura ou clube do livro está mais intimamente ligada à comercialização de livros e no aquecimento da indústria cultural do que na promoção da leitura e na formação de leitores e de profissionais que possam conduzir pessoas ao mundo da leitura. 
Há várias denominações encontradas na literatura como: o clube do livro, o círculo do livro, clube de leitura, grupo de leitura, roda de leitura etc., porém, pela tamanho continental do Brasil, poucas são as iniciativas como forma de promoção, incentivo e a iniciação de jovens na leitura.

De acordo com Milton (2002), no Brasil o clube do livro, constituído como empresa teve suas atividades iniciadas no ano de 1943. Publicava livros mensalmente com preços aproximadamente a um terço dos livros vendidos nas livrarias. Na época tinham a pretensão de levar livros a muitos lares brasileiros com a intenção de criar uma biblioteca pessoal ou doméstica e, dessa forma, os pais leriam para seus filhos dando início a uma população que tinham em seus lares os primeiros contatos com o livro e consequentemente com a leitura. Segundo Milton (2002, p. 140) "O Clube do livro também compartilhava a idéia de que os livros eram fundamentais para a formação da nação brasileira e a melhor maneira de ampliar a cultura era disseminá-los." Esses clubes tinham a

[...] missão de levar livros baratos ao maior número de pessoas, dando-Ihes a possibilidades de montar uma biblioteca em casa. Isso as enriqueceria culturalmente e as estimularia a comprar mais livros, e o aumento nas vendas de livros seria o fundamento do progresso no Brasil. (MILTON, 2002, p. 36).

Como se pode constatar, os clubes viam o livro como um objeto, mas também como fonte de sabedoria. Como este objeto, o livro, estava um pouco fora do alcance da maioria da população em virtude de questões econômicas, culturais e da não oportunidade fora das grandes capitais. Via-se na formação do clube uma forma de ganhar dinheiro levando cultura e sabedoria a baixo custo para o povo. A ideia não era de todo ruim para a leitura e para as editoras, supondo que quem comprasse os livros, também os lessem, na mesma medida em que compravam. Assim, a fonte de leitura chegava aos lares, mas cabia aos compradores a leitura e o exemplo dentro de casa, para os filhos, portanto, a mediação familiar.

Todas as suas estratégias eram voltadas para o comércio de livros e não na promoção da leitura, mas seus associados eram levados a acreditar no poder de transformação cultural contidos neles.

Esses clubes surgiram no Brasil seguindo modelos importados da França, Inglaterra e Estados Unidos, entre outros e alavancaram as vendas em algumas editoras, hoje ainda conhecidas, como a Editora Globo, Martins Fontes, Saraiva, 
Ática, Record etc., e todas visavam acima de tudo o lucro e a expansão editorial e tinham em comum o pensamento de que os clubes de livros,

[...] oferecem uma série de vantagens ao leitor: redução de preço, remessa postal de livros - o que é particularmente importante em áreas distantes de livrarias, [...] um catálogo reduzido ou até mesmo recomendações de títulos mensais, de tal maneira que os leitores não precisem escolher, pois para muitas pessoas a escolha é algo desconcertante. Além dessas vantagens, não é preciso que o leitor se dirija à livraria, considerada muitas vezes um ambiente burguês. (MILTON, 2002, p. 20).

Assim, eles cumpriram de forma, muitas vezes reducionistas, a responsabilidade de mediadores entre o livro e o leitor ou os textos e seus leitores.

De acordo com o referido autor, Monteiro Lobato teve influência significante, nessa época, juntando-se aos editores e aos clubes na tentativa de alavancar o mercado editorial e popularizar o livro e a leitura, "[...] fazendo com que fosse vendido como mercadoria em lojas e bancas de jornal, produzindo capas atraentes e reduzindo muito da aura que o circundava. A leitura deveria tornar-se, segundo Lobato, uma atividade recreativa." (MILTON, 2002, p. 27).

Essa modalidade de clube é muito vantajosa para o editor, que não precisa mais se esforçar tanto para convencer o associado a comprar e ler o próximo livro. Com um catálogo reduzido o leitor fica com pouca possibilidade de escolha, vindo a ler o que tem disponível ou o que lhe foi imposto e oferecido. Como se pode observar, a maioria dos clubes surge com a intenção de vendas, a geração de lucros e a competitividade entre as editoras.

Aparentemente, o termo clube do livro remete a vendas e obtenção de lucros enquanto clube de leitura está voltado para a leitura, análise e discussão da trama. Hoje basicamente há três principais categorias de clubes:

[...] a primeira, com bases econômicas (todo mês o leitor paga um valor fixo e recebe uma determinada obra); a segunda trata - se da reserva de um espaço onde são disponibilizados livros, revistas e outros documentos para leitura e empréstimo e a terceira criação de um grupo de leitores que se reúnem para ler e discutir um determinado texto/livro. (BORTOLIN; ALMEIDA JÚNIOR, 2011, p. 7, grifo do autor).

O clube de leitura aqui analisado pertence à última categoria, tendo como aliada a segunda. A proposta é de que a biblioteca escolar seja o lugar de seleção, 
escolhas e empréstimos; uma divisão, dentro da biblioteca, exclusiva e devidamente ambientada para os encontros de leitura e discussão dos textos escolhidos pelos grupos.

Buscando na literatura nacional e estrangeira, definições para clube de leitura foram encontradas as seguintes definições:

[...] clube de leitura é toda iniciativa de um grupo de leitores experientes ou iniciantes, tendo como característica básica a realização de reuniões periódicas, presenciais ou virtuais com a finalidade de ler e discutir determinado texto/livro, em sua maioria, literários. (BORTOLIN; ALMEIDA JÚNIOR, 2011, p. 7).

Pesquisadores da Universidad de Los Andes - Escuela de Educación que também investigaram as atividades do clube de leitura com enfoque na leitura e na escrita envolvendo, além da comunidade escolar, também a família. Peña Gonzalez e Barboza P. (2002, p. 171) afirmam que:

El Club de Lectura Escolar es una organizanización alrededor de la cual se agrupan padres, representantes, alunos y docentes con la finalidade de propiciar espacios que conduzcan a la utilización de la lectura y la escritura con diversos fines. Sus propósitos, funcionamento y estrutura organizativa depende de los acuerdos a que lleguen sus membros.

Tomou-se também como parâmetro as experiências da Biblioteca Pública de Évora em Portugal, que além do grupo de leitura para adultos, que foi denominado de Clube de Leitura, possui também a versão jovem deste mesmo grupo, o Grupo de Leitura Juvenil Gaspachos de Letras, para apoiar as atividades de leitura dos adolescentes, pois

Ler é uma actividade solitária, mas quando un livro nos toca ou estimula, é natural querer discuti-lo con outra pessoa. Un Grupo de Leitura dá-lhe essa oportunidade. Un grupo destes também o (a) encoraja a pensar un pouco mais sobre os livros que leu - porque gosta de uns e detesta outros. (BIBLIOTECA..., 2013, Não paginado).

O que fazer em um clube de leitura? O que ler? Como proceder às discussões? Que atividades o clube pode proporcionar e como são desenvolvidas? 
Essas perguntas podem ser respondidas da seguinte forma: o clube, acima de tudo, deve proporcionar a liberdade de escolha do leitor (até para diferenciar do rigor existente na sala de aula). Além da leitura, o clube pode proporcionar ao leitor o contato com diversas atividades e narrativas, como o teatro, a música, o cinema e outras. Quem estiver indeciso sobre o que ler, acaba experimentando um pouco de tudo como: aventura, poesia, romance policial, até ficar pronto para decidir por um gênero literário ou mais.

Assim, para subsidiar os mediadores de leitura elaborou-se um Manual de Instruções para um clube de leitura na escola.

\section{MANUAL DE INSTRUÇÕES ${ }^{1}$ PARA UM CLUBE DE LEITURA}

Este manual destina-se a bibliotecários, professores, pais e técnicos administrativos que pretendem criar um clube de leitura na biblioteca escolar tendo como objetivo a promoção da literatura e a inserção dos jovens no mundo da leitura.

O conteúdo aqui proposto tem a intenção de dar um norte aos profissionais da biblioteca escolar nas atividades de leitura, podendo ser adaptada para outras situações, atendendo assim necessidades locais ou particulares de pessoas ou grupos específicos.

A intenção do clube de leitura não é somente propor leitura, mas compartilhar experiências de diversas narrativas, buscando valorizar a leitura dos adolescentes que já leem com a intenção de atrair os que ainda não leem com frequência. Além disso, valorizar a biblioteca da escola, desafiar os jovens a conhecer seu acervo literário encontrando novas possibilidades de leituras, se sentindo satisfeito em passar parte do seu tempo em contato com o livro, e a literatura na biblioteca.

De acordo com Maria (2009, p. 45)

[...] a educação do gosto se faz por encontros, aos poucos, paulatinamente. E, se no início o jovem se apaixona pela história e pelos personagens, se chega a última página tendo a curiosidade como dínamo e os lances do enredo a acioná-lo, quando acontecer o contato com as grandes obras da literatura, este jovem já terá um referencial para comparação. [...] que o prazer da leitura é ingrediente básico, fundamental e indispensável na formação de leitores, não acho justo esperar que estudantes com pouca ou

\footnotetext{
${ }^{1}$ A inspiração para esse título, foi o livro: ZIRALDO. Brasil: manual de instruções. São Paulo:
} Melhoramentos, 1986. 
nenhuma leitura de obras literárias, às vezes nenhuma leitura de livro algum, comecem a ler pelas obras-primas.

Buscar florescer nos adolescentes aquilo que eles têm de melhor nessa fase de desenvolvimento que é a curiosidade, o ímpeto de conhecer coisas novas. Proporcionar a eles momentos agradáveis em contato com a leitura literária e estimulá-los a compartilhar essas experiências com outros jovens no clube de leitura, também é um dos objetivos desse espaço de convivência.

Visando a gestão de um clube de leitura, baseou-se em áreas como: Administração, Letras, Educação, Biblioteconomia, estabeleceu-se alguns fundamentos, entre eles: a missão, os valores, a visão, normas e regulamentos para o seu funcionamento.

\section{MISSÃO}

Despertar o interesse e promover o gosto pela leitura literária, de forma livre. Criar um espaço comunitário propício para a leitura, o diálogo e o aprendizado estético, onde os adolescentes e adultos queiram estar.

\section{VALORES}

Valorizar a leitura e o gosto literário de cada um. Despertar o interesse e o gosto pela literatura nacional e universal como forma de conhecer, valorizar e ampliar o conhecimento da cultura.

\section{VISÃO}

Envolver a comunidade escolar por meio da leitura, ampliar sua visão de mundo, promover a interação cultural comunitária e pessoal.

Quanto as Normas e Regulamentos as que serão apresentadas a seguir tiveram inspiração em algumas perguntas existentes no site da Biblioteca Pública de Évora (Portugal), sendo que as respostas foram adaptadas à realidade das bibliotecas escolares brasileiras. 


\section{NORMAS E REGULAMENTOS}

"Porquê um Grupo de Leitura? Ler é uma actividade solitária, mas quando um livro nos toca ou estimula, é natural querer discuti-lo com outra pessoa. Um Grupo de Leitura dá-Ihe essa oportunidade. Um grupo destes também o (a) encoraja a pensar um pouco mais sobre os livros que leu - porque gosta de uns e detesta outros." (BIBLIOTECA..., 2013, Não paginado).

\section{Quantas pessoas podem participar?}

Não há um número máximo de participantes, porém um grupo muito pequeno pode desestimular as reuniões a discussão e um muito grande poderá prolongar o tempo. Nesse caso será necessário estabelecer algumas regras.

\section{Onde é que as reuniões têm lugar?}

"Uma possibilidade é em casa das próprias pessoas de um modo rotativo. Muitos têm lugar em livrarias, escolas, bibliotecas - mesmo em cafés ou em bares." (BIBLIOTECA..., 2013, Não paginado). Nessa proposta o espaço é a biblioteca escolar.

\section{Quem pode participar?}

Alunos, professores, pais, técnicos administrativos, enfim toda a comunidade escolar.

\section{Qual a idade permitida?}

Sem delimitação de idade e a participação deve ser voluntária. Vale destacar que pessoas com a idade próxima tendem a ter os interesses semelhantes, por exemplo, o estilo, as temáticas.

\section{Quantas vezes? E durante quanto tempo?}

A regra mais frequente parece ser uma vez por mês, mas poderá ser menor esse intervalo - semanal ou quinzenal. Quanto ao tempo de duração das reuniões, no máximo duas horas.

\section{O que é que isto implica?}

Para participar de um clube de leitura o leitor terá que ter lido o livro escolhido, mas a não leitura não o excluí de participar dos encontros.

\section{Falamos sobre o quê?}

"Começamos com a sua reacção ao livro - adorou, detestou ou ficou indiferente? Porquê? Pensemos em seguida sobre o que o livro realmente é os seus temas. As personagens parecem-lhe reais? Com quem simpatiza? Há uma parte ou cena particularmente interessante? $O$ livro veicula uma mensagem? O que é que lhe diz sobre o seu autor? Lembra-Ihe alguma outra coisa? Quer ler mais do mesmo autor? Se ganhou um prémio, será que o mereceu? A discussão pode por vezes ser ainda mais estimulante se não gostou do livro. Perdeu o interesse no livro? Porquê? As personagens? A própria história? Muito confuso - ou demasiado óbvio? Descrição a mais ou a menos?" (BIBLIOTECA..., 2013, Não paginado). 
O contato com a diversidade de gêneros literários tende a construir um leitor plural. Com a intenção de subsidiar os mediadores de leitura em um clube de leitura, apresenta-se no quadro a seguir definições esclarecedoras.

\begin{tabular}{|c|c|}
\hline Gêneros literários & Definições \\
\hline $\begin{array}{l}\text { Clássicos da } \\
\text { literatura brasileira }\end{array}$ & $\begin{array}{l}\text { "A literatura é uma forma expressiva e da imaginação } \\
\text { que contribui para o conhecimento. Cada um de nós } \\
\text { edita a sua realidade por intermédio de um modo de } \\
\text { pensar profundamente influenciado pela literatura, a } \\
\text { história e histórias, bem como os mitos da sua cultura. } \\
\text { 'As literaturas nacionais' são cachos de ideias, de } \\
\text { associações e de poderosas identificações que visam } \\
\text { separar-'nos' de 'outros' e que são extremamente } \\
\text { difíceis de alterar." (JANKOWSKI, 2006, p. 24). }\end{array}$ \\
\hline Poesia & $\begin{array}{l}\text { "Arte de compor ou escrever em versos livres, providos } \\
\text { de rima, geralmente com associações harmônicas de } \\
\text { palavras, ritmos e imagem. Textos curtos que desperta } \\
\text { emoção, enlevo, sentimentos de beleza e estética." } \\
\text { (HOUAISS, VILLAR, FRANCO, 2009, p. 1514). }\end{array}$ \\
\hline Literatura de Cordel & $\begin{array}{l}\text { "A literatura de cordel é uma narrativa em que se } \\
\text { retrata, com forte apelo linguístico e cultural nordestino, } \\
\text { fatos diversos da sociedade e da realidade vivida por } \\
\text { aquele povo. Tem em seus versos a rima e a } \\
\text { sonoridade. A literatura de cordel vem do fato de que } \\
\text { costumavam ser pendurada em fios, formando uma } \\
\text { espécie de varal, cordão." (LAROUSSE, 1998a, p. 236). }\end{array}$ \\
\hline Contos & $\begin{array}{l}\text { "O conto é um texto narrativo breve, e de ficção, } \\
\text { geralmente em prosa, que conta situações rotineiras, } \\
\text { curta, engraçada e até folclores (conto popular)." } \\
\text { (SALVATORE, 1990, p. 31). }\end{array}$ \\
\hline Crônicas & $\begin{array}{l}\text { "A Crônica é uma narrativa informal, ligada à vida } \\
\text { cotidiana, com linguagem coloquial, breve, com um } \\
\text { toque de humor e crítica." (SÁ, 2001, p. 24). }\end{array}$ \\
\hline
\end{tabular}


Histórias em Quadrinhos

\begin{abstract}
"As histórias em quadrinhos são uma forma de narração figurativa constituída por imagens desenhadas, unidas a formas verbais específicas (balão). [...] Narração em sequência de imagens, a continuidade das personagens de uma sequência para outra e o diálogo incluído no balão. Sua popularidade provou que o suspense e a ação agradavam os leitores mais jovens. O interesse maior dos quadrinhos reside no fato de estes registrarem, com notável fidelidade, os acontecimentos sociais e econômicos." (LAROUSSE, 1998b, p. 4846).
\end{abstract}

Ainda com o objetivo de colaborar com os diversos profissionais que atuam na biblioteca escolar incluímos nesse trabalho algumas sugestões de atividades para um clube de leitura escolar.

\begin{tabular}{|l|l|}
\hline Feira de Literatura & $\begin{array}{l}\text { "O objetivo é fazer com que a criança compre um livro do } \\
\text { gosto dela ou troque entre os amigos de sala. Esse } \\
\text { projeto ajuda as crianças a encontrar novos livros para a } \\
\text { realização da leitura, pois terá contato obras oriundas de } \\
\text { livrarias e sebos." }\end{array}$ \\
\hline Exibição de filmes & $\begin{array}{l}\text { "A exibição de filmes pode ser realizada tanto para o } \\
\text { público infantil quanto adulto. Após essa atividade, } \\
\text { destaca-se o tema do filme, podendo ser convidado um } \\
\text { especialista para realizar comentários." }\end{array}$ \\
\hline Oficinas de leitura & $\begin{array}{l}\text { "Fomenta a cultura e a leitura, por meio de narrativas, } \\
\text { roda de histórias, dramatizações de produções literárias } \\
\text { e artísticas." }\end{array}$ \\
\hline Conto dramatizado & $\begin{array}{l}\text { "O conto dramatizado, além de contar história, possibilita } \\
\text { adaptá-la para o teatro, com a participação direta de } \\
\text { atores, marionetes, bonecos de pano e outros recursos." }\end{array}$ \\
\hline $\begin{array}{l}\text { Encontros com } \\
\text { escritores }\end{array}$ & $\begin{array}{l}\text { "Promove a aproximação entre leitor-autor e podem ser } \\
\text { realizados com lançamentos de livros, organização de } \\
\text { sessões de autógrafos, conversas informais e debates." }\end{array}$ \\
\hline Lançamentos de & $\begin{array}{l}\text { "Divulgam livros publicados recentemente e comumente } \\
\text { é realizada com a presença do autor, para que ele } \\
\text { distribua autógrafos." }\end{array}$ \\
\hline Banca de troca- & $\begin{array}{l}\text { "Reúne determinado grupo de pessoas, geralmente, da } \\
\text { mesma faixa etária de idade, para a troca de materiais } \\
\text { específicos." }\end{array}$ \\
\hline troca de gibis
\end{tabular}




\begin{tabular}{|l|l|}
\hline $\begin{array}{l}\text { Discussão com os } \\
\text { pais sobre leitura }\end{array}$ & $\begin{array}{l}\text { "Propicia aos pais momentos de troca de ideias e } \\
\text { esclarecimento de dúvidas a respeito da literatura, da } \\
\text { formação de leitores. Essa atividade tende a estimulá-los } \\
\text { a realizar leitura no lar com os filhos." }\end{array}$ \\
\hline $\begin{array}{l}\text { Murais e } \\
\text { exposições de } \\
\text { produções dos } \\
\text { alunos - }\end{array}$ & $\begin{array}{l}\text { "Contribuem para que a criança leia livros e também } \\
\text { reinventar histórias. Alguns cuidados devem ser tomados } \\
\text { no desenvolver dessa atividade: eles devem ficar em } \\
\text { local de fácil acesso e conter notícias acerca de resumo } \\
\text { de filmes, livros e peças, notas acerca de concursos, } \\
\text { feiras, slogans, opiniões sobre lançamentos, autores e } \\
\text { desenhos feitos a partir da própria história etc." }\end{array}$ \\
\hline
\end{tabular}

Fonte: Gomes e Bortolin (2011, p. 165).

Outra preocupação ao compor este Manual foi a atualização constante dos mediadores, portanto, incluiu-se a seguir duas listagem, a primeira de uma Biblioteca Básica e a segunda uma Filmoteca Básica, elaborada por nós com o objetivo de partilha.

\section{BIBLIOTECA BÁSICA PARA A FORMAÇÃO DO MEDIADOR DE LEITURA}

ABRAMOVICH, Fanny. Literatura infantil: gostosuras e bobices. São Paulo: Scipione, 1989. (Série pensamento e ação no magistério, 7).

ARIÈS, Philippe. História social da criança e da família. 2. ed. Rio de Janeiro: LTC, 1981.

BARROS, Maria Helena T.C. de; BORTOLIN, Sueli; SILVA, Rovilson José da Leitura: mediação e mediadores. São Paulo: FA Editora, 2006.

BETTELHEIM, Bruno. A Psicanálise dos contos de fadas. 7. ed. Rio de Janeiro: Paz e Terra, 1980.

BIBE-LUYTEN, Sonia M. O Que é histórias em quadrinhos. 2. ed. São Paulo: Brasiliense, 1985. (Coleção primeiros passos).

BORDINI, Maria da Glória; AGUIAR, Vera Teixeira. Literatura: a formação do leitor alternativas metodológicas. Porto Alegre: Mercado Aberto, 1993.

CADERMATORI, Ligia. O Que é literatura infantil. 2. ed. São Paulo: Brasiliense, 2010. (Coleção primeiros passos, 163).

CAMARGO, Luís. Ilustração do livro infantil. Belo Horizonte: Lê, 1995. (Coleção Apoio).

CASCUDO, Luís da Câmara. Literatura oral no Brasil. 2. ed. São Paulo: Global, 2009. 
COELHO, Betty. Contar histórias: uma arte sem idade. São Paulo: Ática, 1999.

COELHO, Nelly Novaes. Literatura infantil: teoria, análise e didática. 7. ed. São Paulo: Moderna, 2002.

COLOMER, Teresa. A Formação do leitor literário: narrativa infantil e juvenil atual. São Paulo: Global, 2003.

DEMO, Pedro. Leitores para sempre. Porto Alegre: Editora Mediação, 2006.

FREIRE, Paulo. A importância do ato de ler: em três artigos que se completam. 40. ed. São Paulo: Autores Associados, 2003.

LAJOLO, Marisa. Do mundo da leitura para a leitura do mundo. São Paulo: Ática, 1999.

. Literatura: leitores \& leitura. São Paulo: Moderna, 2001.

LONTRA, Hilda Orquídea H. Histórias de leitores. Brasília: UNB, 2006.

LUYTEN, Joseph M. O Que é literatura popular. São Paulo: Brasiliense, 1983. (Coleção primeiros passos, 98).

MACHADO, Ana Maria. Contracorrente: conversas sobre leitura e política. São Paulo: Ática, 1999.

MANGUEL, Alberto. Lendo imagens. São Paulo: Companhia das Letras, 2001. Uma história da leitura. São Paulo: Companhia das Letras, 1997.

MARIA, Luzia de. O clube do livro: ser leitor - que diferença faz? São Paulo: Globo, 2009.

MARTINS, Maria Helena. O que é leitura. São Paulo: Brasiliense, 1983. (Coleção primeiros passos, 74).

MILTON, John. O Clube do Livro e as traduções. Bauru, SP: EDUSC, 2002.

PAIVA, Aparecida; MARTINS, Aracy; PAULINO, Graça; VERSIANI, Zélia (Orgs.). Leituras literárias: discursos transitivos. Belo Horizonte: Ceale; Autêntica, 2005.

PENNAC, Daniel. Como um romance. Rio de Janeiro: Rocco, 1997.

PERROTTI, Edmir. Confinamento cultural, infância e leitura. São Paulo:

Summus, 1990. (Coleção novas buscas em educação, v.38).

O texto sedutor na literatura infantil. São Paulo: Ícone, 1986.

POSTMAN, Neil. O Desaparecimento da infância. Rio de Janeiro: Graphia, 1999.

PRADO, Jason; CONDINI, Paulo (Org.). A formação do leitor: pontos de vista.

Rio de Janeiro: Argus, 1999. Disponível em:

<http://solivrosparadownload.blogspot.com.br/2008/01/jason-prado-paulo-condiniformacao-do.html>. 
RÖSING, Tania Mariza Kuchenbecker. (Org.) Do livro ao CD-ROM: novas navegações. Passo Fundo: EDIUPF, 1999.

SANTOS, Fabiano dos; MARQUES NETO, José Castilho; ROSING, Tania Mariza Kuchenbecker. Mediação de leitura: discussões e alternativas para a formação de leitores. São Paulo: Global, 2009.

SCHWALBE, Will. O Clube de leitura do fim da vida: um história real sobre a perda, clebração e o poder da leitura. Rio de Janeiro: Objetiva, 2013.

SOUZA, Ângela Leite de. Contos de fada: Grimm e a literatura oral no Brasil. Belo Horizonte: Lê, 1996. (Coleção Apoio).

TODOROV, Tzvetan. A literatura em perigo. Rio de Janeiro: Difel Brasil. 2009.

\section{FILMOTECA BÁSICA PARA A FORMAÇÃO DO MEDIADOR DE LEITURA}

AUSTRÁLIA.Direção: BazLuhrmann. Produção: G. Mac Brown, Catherine Knapman e BazLuhrmann. Distribuidora: 20th Century Fox Film Corporation, 2008. 1 DVD (165 min).color. Título Original: Australia.

O CONTADOR de histórias. Direção: Luiz Villaça. Produção: Francisco Ramalho Jr., Denise Fraga. [S.L.]: Ramalho Filmes, Distribuidora: Warner Bros, 2009. 1 DVD (100 min.), color. Baseado na biografia de Roberto Carlos Ramos

O CLUBE de leitura de Jane Austen. Direção: Robin Swicord. Produção: John Calley, Julie Lynn e Diana Napper. Produtora: John Calley. Roteiro: Robin Swicord, Productions / Mockingbird Pictures. [S.L], Distribuidora: Sony Pictures Classics, 2007. 1 DVD (115 min.), color.Baseado no livro de Karen Joy Fowler.Título original: The Jane Austen Book ClubO LEITOR. Direção: Stephen Daldry. Produção: Donna Gigliotti, Anthony Minghella, Redmond Morris e Sydney Pollack. [S.L.]: The Weinstein Company/NeunteBabelsberg Film/ Mirage Enterprises Distribuidora/Imagem Filmes, 2008. 1 DVD (124 min.), color. Título original: The reader.

MATILDA. Direção: Denny DeVito. Produção: DennyDeVito,MichaelSamberg, Stacey Sher. Intérpretes:RheaPerlman, EmbethDavidtz, Paul Reubens, Treacey Walter. Roteiro:Robin Swicor. Música: David Neuman. Estados Unidos: Tristar Pictures, 1996. 1 DVD (101 min).

NARRADORES de Javé. Direção: elianeCaffé. Produção: Eliane Caffé, Luis Alberto de Abreu. Intérpretes: Nelson Xavier, José Dumont. Produção:André Montenegro, Vânia Catani. Música de: DJ Dolores, Orquestra Santa Massa. Brasil [s.n.] 2003. 1 DVD (85 min).

O NOME DA ROSA. Direção: Jean-JaquesAnnaud. Produção: Bernd Eichinger. Intérpretes: Sean Connery, Christian Slater, F. Murray Abraham. Roteiro: JeanJaquesAnnaud, Howard Franklin. Inglaterra: Cristaldfilm, 1986. 1 DVD (130min). 
NUNCA TE VI, sempre te amei. Direção: David Hugh Jones. Produção: mel books. Intérpretes:Anne Bancroft, Anthony Hopkins, Judi Dench. Roteiro:Estados Unidos: Columbia Pictures, 1986. 1 DVD (99 min).

O ÓLEO de Lorenzo. Direção: George Miller. Produção: George Miller. Intérpretes: Peter Ustinov, Kathleen Wilhoite. Roteiro:George Miller. Estados Unidos: Universal Pictures, 1992. DVD (129 min).

PHILADELPHIA. Direção: Jonathan Demme. Produção: Jonathan Demme. Intérpretes: Tom Hanks, Denzel Washington, Mary Steenburgen. Roteiro: Ron Nyswaner. Inglaterra, 1993. 1 DVD (120 min).

A PARTIDA. Direção: YojiroTakita. Roteiro: Roteiro:KundoKoyama. Produção: Toshiaki Nakazawa, ToshihisaWatai e IchirôNobukuni. [S.I.]: Distribuidora: Paris Filmes, 2008. 1 DVD (130 min.) color. Título original: Okuribito.

SOCIEDADE dos poetas mortos. Direção: peter Weir. Intérpretes: Robin Williams, Ethan Hawke, Robert Sean Leonard. Roteiro: Tom Schulman. Inglaterra: Touchstone Pictures, 1989. 1 DVD (128 min).

TEMPOS de paz. Direção: Daniel Filho. Co-Produção: Globo Filmes, Lereby Produções e Downtown Filmes. Roteiro: Bosco Brasil. [S.L.], 2009. 1 DVD (80 min.), color.

TOMATES verdes fritos. Direção: Jon Avnet. [S.I.]: Distribuidora: Universal Pictures, 1991. 1 DVD (136 min.), color. Título original: Fried Green Tomatoes.

UM SONHO de liberdade. Direção:Frank Darabont. Produção:Niki Marvin. Intérpretes:Tim Robbins, Morgan Freeman, Bob Gunton. Roteiro:Frank Darabont. Estados Unidos:Warner Bross, 1994. 1 DVD (142 min).

\section{DESAFIOS CONSTANTES E CONSIDERAÇÕES FINAIS}

O livro é, ainda, um objeto de múltiplas facetas. Ele foi um dia considerado objeto de arte, motivo de perseguição e censura, já pertenceu à elite e hoje é um produto comum totalmente comercializável e ao mesmo tempo continua tendo um valor cultural incalculável, tão ao alcance de quase todos e ao mesmo tempo praticamente intocável.

A família é o primeiro espaço para a formação de leitores, mas é no período escolar que esta mediação é intensificada. A biblioteca ao cumprir esse papel, deve fazê-lo de maneira ampliada e não apenas nos documentos impressos. O leitor precisa ter acesso à filmes, obras de artes, peças musicais, objetos históricos, entre outros. 
Formar leitor não é tarefa fácil e leva muito tempo. Quanto? Quem sabe, duas gerações, mais? Difícil precisar, pois é necessário mudar ou construir uma cultura com pessoas que leem e percebem a leitura como fator de mudança social, acreditando na leitura como potencial para formar pessoas críticas, capazes de pensar a sociedade e não apenas aceitá-la como tal.

Necessita-se urgentemente pensar as estruturas das escolas e principalmente das bibliotecas para que sejam ambientes agradáveis e acolhedores, para expandir a ação de todos os mediadores escolares. Esse conceito de um espaço harmonioso, com mobiliário moderno e descontraído próprio para um público infantojuvenil é uma tentativa de atrair e encantar os adolescentes, enfim tornar a biblioteca escolar um ambiente em condições físicas favoráveis.

A intenção da produção desse Manual foi, de alguma forma, dar suporte e prover ideias ao mediador de leitura em suas ações visando dar vida ao espaço. As atividades sugeridas tendem a dar visibilidade à biblioteca, ao bibliotecário e à escola, cumprindo, assim, sua missão de propiciar leitura, lazer e cultura aos alunos e à comunidade.

As ideias aqui propostas servirão como marco inicial aos bibliotecários que devem estar abertos à outras possibilidades, principalmente, em tempos de novas tecnologias a serem exploradas.

A lista básica de sugestão de livros e de filmes, incluída neste Manual, é apenas uma inciativa para subsidiar o mediador de biblioteca em suas leituras; portanto não deve ser motivo de acomodação, pelo contrário, um incentivo para a busca constante de outros aprendizados e atualizações no mundo da leitura. Espera-se também que os profissionais encontrem subsídios iniciais para compreender melhor a importância da leitura, estando, em cada mediação, aberto para trocas, isto é, receber recomendações de seus mediandos, afinal leitura sem partilha, não enriquece a relação biblioteca e aluno.

Visando minimizar distorções como as mencionadas no resultado dessa pesquisa, a proposta do Manual de Instrução para a criação, manutenção e gestão de um clube de leitura é uma iniciativa que visa contribuir para a formação de leitores.

Chegamos à conclusão de que são muitas perguntas que necessitam de respostas, mas uma questão está decidida. Para formar um leitor é necessário que a 
biblioteca, além de ser um espaço acolhedor, o mediador que nela está deve ser capaz de implementar ações concretas de leituras.

\section{REFERÊNCIAS}

BARBOSA, José Juvêncio. Alfabetização e leitura. 2. ed. rev. São Paulo: Cortez, 1994.

BARROS, Maria Helena T. C. de. A mediação da leitura na biblioteca. In: BARROS, Maria Helena T. C.; BORTOLIN, Sueli; SILVA, Rovilson José da. Leitura: mediação e mediador. São Paulo: FA, 2006. p. 17-22.

BIBLIOTECA PÚBLICA DE ÉVORA (Portugal). Actividades: grupo de leitura. 2013. Disponível em:

<http://www.evora.net/bpe/Actividades/Grupos_leitura/Grupo\%20de\%20leitura.htm>. Acesso em: 25 nov. 2013.

BORGES, Silvia Bortolin; BORTOLIN, Sueli. Hora da história: toda criança merece. In: BARROS, Maria Helena T. C. de; BORTOLIN, Sueli; SILVA, Rovilson José da. Leitura: mediação e mediador. São Paulo: FA, 2006. p. 139-146.

BORTOLIN, Sueli. A mediação de leitura nos espaços infanto-juvenis. In: BARROS, Maria Helena T. C. de; BORTOLIN, Sueli; SILVA, Rovilson José da. Leitura: mediação e mediador. São Paulo: FA, 2006. p. 65-74.

BORTOLIN, Sueli; ALMEIDA JÚNIOR, Oswaldo Francisco de. Memória de uma bibliotecária-personagem e a mediação oral da literatura com adolescentes. In: SEMINÁRIO EM CIÊNCIA DA INFORMAÇÃO, 4., 2011. Londrina. Anais eletrônicos... Londrina: MPGI/UEL, 2011. p. 1-16. Disponível em: <http://www.uel.br/eventos/cinf/index.php/secin2011/secin2011/paper/viewFile/32/6>. Acesso em: 25 mar. 2013.

BRITTO, Luiz Percival Leme. O papel da biblioteca na formação de leitores. In: BRASIL. Ministério da Educação. Secretaria de Educação Básica. Biblioteca escolar: que espaço é esse? Boletim TV Escola/Salto para o Futuro, v. 21, n. 14, Rio de Janeiro, out. 2011. Disponível em:

<http://tvbrasil.org.br/fotos/salto/series/14051114-BibliotecaEscolar.pdf>. Acesso em: 5 mar. 2012.

CANDIDO, Antonio. A literatura e a formação do homem. Ciência e Cultura, São Paulo, v. 24, n. 9, p. 803-809, set. 1972.

FREIRE, Paulo. A importância do ato de ler: em três artigos que se completam. 13. ed. São Paulo: Cortez, 1986.

GOMES, Luciano Ferreira; BORTOLIN, Sueli. Biblioteca escolar e a mediação. Semina: Ciências Sociais e Humanas, Londrina, v. 32, n. 2, p. 157-170, jul./dez. 2011. Disponível em: 
<http://www.uel.br/revistas/uel/index.php/seminasoc/article/view/11962/13823>. Acesso em: 28 ago. 2014.

HOUAISS, Antônio; VILLAR, Mauro de Salles; FRANCO, Francisco Manoel de Mello. Dicionário Houaiss da língua portuguesa. Rio de Janeiro: Objetiva, 2009.

JANKOWSKI, Piotr et al. Clubes de leitura para adultos: manual para mentores. Portalegre: Instituto Politécnico de Portalegre, 2006. Disponível em: <http://repositorio.ipcb.pt/handle/10400.11/370>. Acesso em: 20 dez. 2012. LAROUSSE cultural: Brasil de a/z. São Paulo: Editora Universo, 1998a.

LAROUSSE. Grande Enciclopédia Larousse Cultural. São Paulo: Nova cultural, 1998b.

MARCONI, Marina de Andrade; LAKATOS, Eva Maria. Técnicas de pesquisa: planejamento e execução de pesquisa... 7. ed. São Paulo: Atlas, 2013.

MARIA, Luzia de. O clube do livro: ser leitor - que diferença faz? São Paulo: Globo, 2009.

MARTINS, Maria Helena. O que é leitura. 2. ed. São Paulo. Brasiliense, 1983.

MILTON, John. O clube do livro e as traduções. Bauru, SP: EDUSC, 2002.

O DIREITO de ser adolescente: oportunidade para reduzir vulnerabilidades e superar desigualdades. Fundo das Nações Unidas para a Infância. Brasília: UNICEF, 2011. 182p. Disponível em: <http://www.unicef.org/brazil/pt/br_sabrep11.pdf>. Acesso em: 08 set. 2014.

ORLANDI, Eni Pulcinelli. Discurso \& leitura. São Paulo: Cortez, 1988.

PARREIRAS, Ninfas. O papel da biblioteca na formação do leitor literário. In: BRASIL. Ministério da Educação. Secretaria de Educação Básica. Biblioteca escolar: que espaço é esse? Boletim TV Escola/Salto para o Futuro, Rio de Janeiro, v. 21, n. 14, out. 2011. Disponível em:

<http://tvbrasil.org.br/fotos/salto/series/14051114-BibliotecaEscolar.pdf>. Acesso em: 5 mar. 2012.

PEÑA GONZÁLEZ, Josefina; BARBOZA P., Francis Delhi. La família em um club de lectura escolar para favorecer laadquisición y desarrollo de lalengua escrita.

Educere Investigación, Venezuela, v. 6, n. 18, p.168-175, jul./sep. 2002. Disponível em: <http://www.redalyc.org/articulo.oa?id=35601806>. Acesso em: 08 set. 2014.

SÁ, Jorge de. A crônica. São Paulo: Ática, 2001.

SALVATORE, D' Onofrio. Teoria do conto. São Paulo: Ática, 1990.

SILVA, Ezequiel Teodoro da. $\mathbf{O}$ ato de ler: fundamentos psicológicos para uma nova pedagogia da leitura. 9. ed. São Paulo: Cortez, 2002.

SILVA, Rovilson José. Projetar a biblioteca da escola: recomendações. In:

BARBALHO, Célia Regina Simonetti et al. Espaços e ambientes para a leitura e informação. Londrina: ABECIN, 2012. p. 157-172. 


\title{
Title
}

Reading Club In the School Library: instruction manual

\begin{abstract}
Introduction: This present study addresses some considerations about the act of reading of the adolescent learner, the role of the reading facilitator in the school library and their actions to keep the student a reader and to gain new readers. Based on this context, we proposed the creation of a Reading Club as a mechanism capable of bringing reading, readers and the reading mediator together so the school library becomes a living organism inside the school.

Objective: To propose a mechanism that can encourage reading in the school library, as well as subsidize the mediator of reading in youth initiation to the taste of reading.

Methodology: Bibliographical studies of literature dealing with the creation and maintenance of a book club, as well as the approach of the terms: reading and mediator of reading in the school library.

Results: The elaboration of a manual with instructions for the creation and maintenance of a Reading Club in the school library with a mission, values, a vision, rules and regulations, as well as, suggestions of books and movies which can subsidize the reading mediators.

Conclusions: It points to the necessity of the preparation of the school librarian since the librarian is the person who is in charge of the library, they should be a professional reference in the act of reading and one of the responsible for the formation and maintenance of readers.
\end{abstract}

Keywords: Mediator from reading. Reading Club. Teenage readers the school.

Título

En el Club de lectura biblioteca escolar: manual de instrucciones

\section{Resumen}

Introducción: El presente estudio plantea algunas consideraciones sobre el acto de la lectura del alumno adolescente, la función del mediador de lectura en la biblioteca escolar y sus acciones para mantener el alumno lector y conquistar nuevos lectores. Con base en este contexto proponemos la elaboración de un Club de Lectura como mecanismo capaz de acercar lectura, lectores y el mediador de lectura convirtiendo así la biblioteca escolar en un organismo vivo dentro de la escuela.

Objetivo: Proponer la creación de un mecanismo que pueda promover la lectura en la biblioteca escolar, así como subvencionar el mediador de la lectura en la iniciación de jóvenes para que cojan el gusto por la lectura.

Metodología: Levantamiento bibliográfico y estudios de las literaturas que abarquen la creación y mantenimiento de un Club de Lectura, del mismo modo que el abordaje de términos de lectura y el mediador de lecturas en la biblioteca escolar.

Resultados: Elaboración de un Manual con instrucciones para la creación y mantenimiento de un Club de lectura en la biblioteca escolar con la misión, los valores, la Visión, normas y reglamentos, sugerencias de actividades culturales, así como la sugerencia de libros y películas que puedan ayudar a los mediadores de lectura. 
Sueli Bortolin; Zineide Pereira dos Santos

Clube de leitura na biblioteca escolar: manual de instruções

Conclusiones: Señala la necesidad de preparación del bibliotecario escolar, pues es la persona que está frente a la biblioteca, debiendo ser un profesional de importancia en el acto de la lectura y también uno de los responsables por la formación y manutención de los lectores.

Palabras clave: Mediador de lectura. Club de lectura. Lectores adolescentes en la escuela.

Recebido em: 12.11.2014

Aceito em: 22.12.2014 